\title{
BMJ open The persistence of adolescent binge drinking into adulthood: findings from a 15-year prospective cohort study
}

Louisa Degenhardt, ${ }^{1,2}$ Christina O'Loughlin, ${ }^{3}$ Wendy Swift, ${ }^{1}$ Helena Romaniuk, ${ }^{3,4,5}$ John Carlin, ${ }^{4,5}$ Carolyn Coffey, ${ }^{3}$ Wayne Hall, ${ }^{6,7}$ George Patton ${ }^{3,4}$

To cite: Degenhardt $\mathrm{L}$, O'Loughlin C, Swift W, et al. The persistence of adolescent binge drinking into adulthood: findings from a 15-year prospective cohort study. BMJ Open 2013;3: e003015. doi:10.1136/ bmjopen-2013-003015

- Prepublication history and additional material for this paper is available online. To view these files please visit the journal online (http://dx.doi.org/10.1136/ bmjopen-2013-003015)

Received 8 April 2013 Revised 17 July 2013 Accepted 19 July 2013

\footnotetext{
${ }^{1}$ National Drug and Alcohol Research Centre, University of NSW, Sydney, New South Wales, Australia

${ }^{2}$ Melbourne School of Population and Global Health, University of Melbourne, Melbourne, Victoria, Australia ${ }^{3}$ Centre for Adolescent Health Murdoch Children's Research Institute, Melbourne, Victoria, Australia

${ }^{4}$ Department of Paediatrics, University of Melbourne, Melbourne, Victoria, Australia ${ }^{5}$ Clinical Epidemiology \& Biostatistics Unit, Murdoch Children's Research Institute, Melbourne, Victoria, Australia ${ }^{6}$ University of Queensland Centre for Clinical Research, University of Queensland, common in adolescence than adulthood. Overall, $35 \%$ of the sample (95\% Cl 33\% to 38\%) reported past-week binge drinking in adolescence and young adulthood and one-third (33\%; $30 \%$ to $35 \%$ ) first reported binge drinking in young adulthood; only $7 \%$ of the sample (6$8 \%$ ) had binge drinking in adolescence but not young adulthood. 'Heavy binge' drinking occurred in adolescence and young adulthood for $9 \%$ (8\% to $10 \%$ ); $8 \%(7 \%$ to $10 \%)$ reported it in adolescence but no longer in young adulthood; and $24 \%$ (22\% to $26 \%$ ) began 'heavy binge' drinking in young adulthood. Among adolescent binge drinkers $(n=821)$, young adult binge and heavy binge drinking were predicted by being male, adolescent antisocial behaviour and adverse consequences of drinking in adolescence.

Conclusions: Binge alcohol use is common and persistent among young Australians. Efforts to prevent the onset of binge drinking during adolescence may substantially reduce harmful patterns of alcohol use in young adulthood.
} Australia

${ }^{7}$ National Addiction Centre Kings College, London, UK

Correspondence to Dr Louisa Degenhardt; I.degenhardt@unsw.edu.au

\section{ABSTRACT}

Objectives: To examine the prevalence of binge drinking in adolescence and its persistence into adulthood in an Australian cohort.

Design: 15-year prospective cohort study.

Setting: Victoria, Australia.

Participants: 1943 adolescents were recruited from secondary schools at age 14-15 years.

Primary outcome measures: Levels of past-week 'binge' drinking (5+ standard drinks on a day, each $10 \mathrm{~g}$ alcohol) and 'heavy binge' drinking (20+ standard drinks on a day for males, 11+ for females) were assessed during six adolescent waves, and across three adult waves up to age 29 years.

Results: Half of the males (52\%) and a third of the females $(34 \%)$ reported past-week adolescent binge drinking. $90 \%$ of male and $70 \%$ of female adolescentonset binge drinkers continued to binge in young adulthood; $70 \%$ of males and $48 \%$ of females who were not adolescent-onset binge drinkers reported young adult binge drinking. Past-week heavy bingeing was less

\section{INTRODUCTION}

Alcohol is a major source of preventable disease burden among young people ${ }^{1}$ : it is thought to contribute to 320000 deaths

\section{ARTICLE SUMMARY}

Article focus

- Alcohol is a major source of preventable disease burden among young people.

- Although young people drink less often than adults, they may consume large amounts in a single session ('binge' drinking).

- We aimed to: (1) examine the persistence of adolescent 'binge' and 'heavy binge' drinking from adolescence to young adulthood; (2) examine which characteristics of adolescent binge drinkers predict the persistence of 'binge' and 'heavy binge' alcohol use into young adulthood.

Key messages

- Half of the males and a third of the females in a cohort of young Australians reported past-week binge drinking in adolescence.

- The overwhelming majority of these adolescent binge drinkers continued to binge drink in young adulthood.

- Past-week binge drinking was reported in at least one young adulthood wave by around $70 \%$ of males and $48 \%$ of females who had not reported past-week binge drinking in adolescence.

- The high rate of persistence of binge drinking into adulthood indicates the need for policies to reduce its onset in adolescence such as limiting availability, increasing costs and discouraging drinking to intoxication.

globally among 15-29 year-olds each year, comprising $9 \%$ of all deaths in this group. ${ }^{2}$ The burden attributable to alcohol use as a risk factor among young people aged 1529 years (20 million disability adjusted life years (DALYs)) is thought to account for one-third of all global alcohol attributable burden (59 million DALYs). ${ }^{3}$

Alcohol use typically begins in adolescence. ${ }^{45}$ Although young people drink less often than adults, ${ }^{4}$ they may consume larger amounts in a single session. ${ }^{6-8}$ Among school students across 14 European countries in 


\section{ARTICLE SUMMARY}

Strengths and limitations of this study

- This well-conducted prospective study, with very high retention, has provided unique prospective data on the persistence of a prevalent and hazardous drinking pattern into adulthood.

- The following limitations do need to be acknowledged. First, non-response in longitudinal studies is often associated with alcohol and drug use. We used multiple imputation to minimise the impact of this potential bias. Second, our data do not capture the full extent of binge drinking in this cohort because not all binge alcohol use will have been captured within the 1 week reference period. Both these limitations mean that if anything, our findings on levels of binge drinking are conservative in estimating total exposure to these levels of drinking overall and over time.

- Third, all data were based on self-report; however, there is reasonable evidence that young people's reports of alcohol use are reliable and valid when they are made in a confidential manner, and without any consequences for disclosing.

- Fourth, we used the same definition of binge and heavy binge drinking in adolescent and young adults. It is likely that the same amount of alcohol will have a greater adverse impact on adolescents than on adults.

2011, 41\% reported past-month 'binge' drinking (5+ standard alcoholic drinks ${ }^{9}$; levels in the UK were $54 \% .^{9}$ Similar drinking levels occur in young Australians. ${ }^{10}$ One in five Australian males and females 16-24 years reported drinking $20+$ and $11+$ standard drinks in a session (each $10 \mathrm{~g}$ alcohol), respectively, at least monthly in the past year. ${ }^{11}$

There have been many studies examining alcohol use among adolescents, ${ }^{12} 13$ risk factors for young adult consumption and alcohol use disorders, ${ }^{14-19}$ and the impact of adolescent use upon health in young adulthood. ${ }^{13}$ However, to our knowledge there has not been a study of the course of adolescent binge drinking in a cohort study of young Australians. ${ }^{20}$ We investigated the persistence of binge drinking into adulthood among Australian young people using a 15-year prospective cohort study of young Australians that assessed alcohol use during adolescence and up to age 29 years. We also examined the predictors of persistence of binge alcohol use into young adulthood among adolescent binge drinkers.

We aimed to

1. Examine the persistence of adolescent 'binge' and 'heavy binge' drinking from adolescence to young adulthood;

2. Examine which characteristics of adolescent binge drinkers predict the persistence of 'binge' and 'heavy binge' alcohol use into young adulthood.

\section{METHODS}

\section{Sample}

Between August 1992 and 2007, we conducted nine waves of interviews with a cohort then resident in the state of Victoria, Australia (for more details see refs. 21 22). At the beginning of the adolescent phase (waves 1 and 2), parental consent was obtained; in adult waves, participants were informed in writing and gave verbal consent.

At baseline, a representative sample of the Victorian population of school pupils aged 14-15 years (year 9) was recruited. Retention in school to year 9 among Victorian young people in 1992-1993 was 98\%. A two-stage cluster sampling procedure was used, with two classes selected at random. At stage 1, 45 schools were randomly chosen from a stratified frame of government, Catholic and independent private schools. At stage 2, one class was selected at random from each participating school, entering in the last part of year 9 (wave 1), followed by a second class in the second wave 6 months later (wave 2). Participants were interviewed at 6-month intervals from 14 to 19 years (waves 3-6) with three waves in young adulthood: 2021 years (wave 7), 24-25 years (wave 8) and 28-29 years (wave 9). In waves 1-6, participants self-administered the questionnaire on laptops, with telephone follow-up of those absent from school; waves 7-9 involved computerassisted telephone interviews. ${ }^{23}$

\section{Measures}

\section{Alcohol consumption}

Alcohol consumption was recorded at all adolescent and adult phases in an alcohol diary by any participants who reporting drinking in the previous week. In the adolescent phase, respondents completed a 7-day alcohol diary. In the adult phase, in order to minimise respondent burden, participants were only asked to complete a 4-day diary including all weekend days (Friday to Sunday) and the most recent weekday. Types of alcohol (beer, cider, spirits, mixed drinks, wine, etc), brand names and the amounts consumed (glass, pint, bottle, can, etc) were recorded. We calculated the number of standard drink units ( $10 \mathrm{~g}$ alcohol) consumed on each day/occasion, and at each wave. Two measures of binge drinking were estimated (using the same definition in adolescent and adult phases).

1. 'Binge' drinking: Defined (at each wave) as having drunk five or more standard drinks (each $10 \mathrm{~g}$ alcohol) on at least 1 day during the diary week. Any binge drinking was defined in adolescence and adulthood as binge drinking on one or more waves during the respective phase. For each phase, we identified the number of waves in which binge drinking occurred: none, one wave and two or more waves (in adolescence, 2+ of five assessment waves; in adulthood, 2+ of three waves). Persistent binge drinking was defined as binge drinking on two or more waves.

2. 'Heavy' binge drinking: Defined as having drunk $>20$ standard drinks for males and $\geq 11$ standard drinks for females on any day over the diary week. ${ }^{11}$ These levels were taken from a previous study of young people, ${ }^{11}$ using the Australian National Health and Medical Research Council definitions of 'high risk' 
drinking for males and females. Any 'heavy' binge drinking in adolescence and adulthood was defined as having done so on any wave. The number of waves in each phase was identified as above. Persistence of 'heavy' binge drinking was defined as drinking at this level on two or more waves (adolescence, $2+$ of five waves; adulthood, 2+ of three waves).

Incident binge drinking was defined as first reporting binge or heavy binge drinking in young adulthood. Continuity of binge drinking and of heavy binge drinking was defined as the same pattern of drinking in adolescence and also adulthood. Discontinuity was defined as adolescent binge or heavy binge drinking without binge/heavy binge drinking in young adulthood.

\section{Prognostic factors}

Adolescent tobacco smoking was assessed at each adolescent wave. Participants who reported smoking daily in the week prior to survey at any one adolescent wave were classified as daily smokers during adolescence.

Adolescent cannabis use was assessed using the reported frequency of use in the previous 6 months at each wave. Maximal cannabis use during the adolescent phases (ie, most frequent level reported across any wave) was categorised as none/occasional and daily/weekly.

Adolescent antisocial behaviour was assessed using 10 items from the Moffitt and Silva self-report early delinquency scale, ${ }^{24}$ which assessed property damage, interpersonal conflict and theft. Participants were asked if they had engaged in any of these behaviours never, once or more than once in the last 6 months. Antisocial behaviour was defined as any antisocial behaviour on more than one adolescent wave, and/or 2+ behaviours in the same wave.

Early onset sexual behaviour: participants were asked if they had ever had sex ('gone all the way' or had sexual intercourse) at each adolescent wave and their age of first sex at each young adulthood wave. Those reporting sexual activity before 16 years were classified as early onset sexually active.

Adolescent mental health was assessed using the Clinical Interview Schedule (CIS-R), ${ }^{25}$ which assesses depression and anxiety in non-clinical populations; a cut-off of $>11$ defines a mixed depression-anxiety state requiring clinical intervention. Mental health problems were summarised as having occurred: never, in one or 2+ adolescent waves.

Adolescent alcohol-related consequences: Eight questions were asked about problems related to alcohol over the past 6 months in all adolescent waves. These were categorised into four types of consequences: intense drinking (drank so much that the next day you could not remember what you said/did); alcohol-related social problems (lost friends, had trouble at school or argued with family, because of drinking); alcohol-related injury, accident or violence (violent and had a fight or had an injury or an accident, because of drinking); and alcoholrelated sexual risk taking (had sex without using contraceptives, had sex without using protection or had sex and regretted it, because of drinking). For each of the four types of consequences, persistence in adolescence was defined as engaging in the behaviour either across multiple waves or more than once on one wave.

\section{Statistical analysis}

We calculated the prevalence of binge drinking at each wave and the number of waves on which each type of binge drinking occurred in adolescence and adulthood. We also estimated the continuity and discontinuity of binge and heavy binge drinking between the two phases. Among those reporting adolescent binge drinking $(n=821)$, logistic regression was used to examine the prognosis for this group in terms of binge drinking. We investigated associations between adolescent predictors and any binge and heavy binge drinking in young adulthood. These associations were initially examined separately and then jointly in multivariable models. Interactions between the adolescent predictors and sex were examined in the multivariable models but the evidence for differential sex effects was weak. In order to retain information from individuals with incomplete data (and thereby minimise the effects of participation bias), the prevalence of binge and heavy binge drinking during adolescent and young adult phases was estimated using multiple imputation ${ }^{26}{ }^{27}$ (see online supplementary appendix). All data analysis was undertaken using Stata V.12. ${ }^{28}$

\section{Role of the funding source}

Funding to support the work for this manuscript was provided by Australian Rotary Health. Data collection for this study was supported by the National Health and Medical Research Council, Australia and the operational infrastructure support programme, Government of Victoria, Australia. The funders had no role in the design, data collection or analysis, data interpretation, writing of the article or decision to publish. The corresponding author had full access to all the data in the study and had final responsibility for the decision to submit for publication.

\section{RESULTS}

From a total of 2032 students, 1943 (95.6\%) participated at least once in adolescence (figure 1); 1756 (53\% female) participated in at least one adult wave and were known to be alive at wave 9; 1282 completed all three adult waves; 293 completed two waves, and 181 completed one wave. By the end of wave 9, nine participants were known to have died, 108 lost to follow-up and 319 refused participation; 1501 participants were interviewed, 1407 of whom did the full (1383) or part ${ }^{24}$ interview schedule and 94 a paper questionnaire. In this paper, we only used adolescent data from waves $2-6$ as over half of the adolescents did not participate in wave 1. 


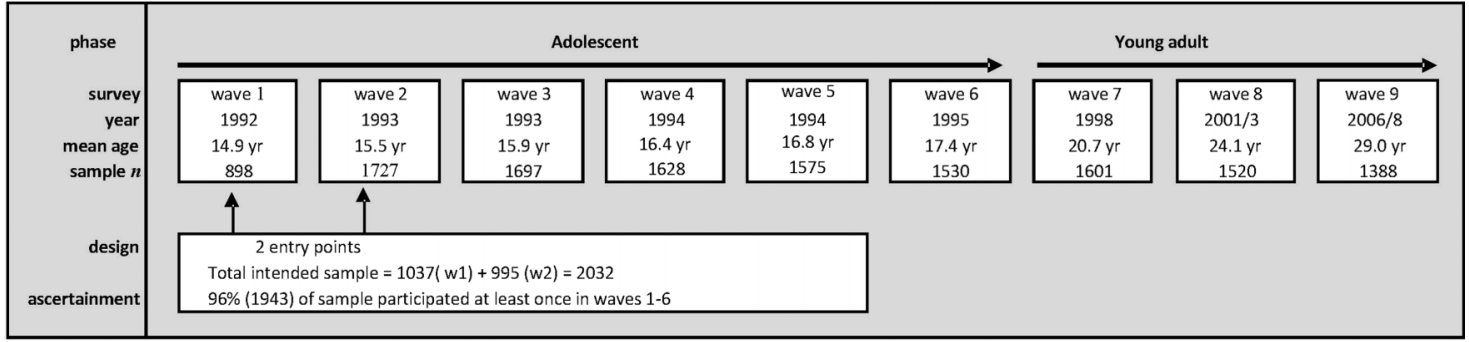

Figure 1 Sampling and ascertainment in the Victorian Adolescent Health Cohort, 1992-2008.

The analysis utilised data from waves 2 to 9 for all participants $(\mathrm{n}=1934)$ who completed the survey at least once in adolescence (waves 2-6) and were alive at wave 9 , with multiple imputation used for incomplete records. The results from the available case analyses are presented in the online supplementary appendix; the pattern of results was broadly similar compared to the imputed data.

\section{Past-week binge drinking}

Almost seven in eight males and two-thirds of the females reported binge drinking in the last week on at least one wave in adolescence and young adulthood. Nearly half of the males and a quarter of the females reported binge drinking both in adolescence and young adulthood. The overwhelming majority of adolescent-onset binge drinkers (9 in 10 male and 7 in 10 female adolescent-onset binge drinkers) continued to binge drink in young adulthood (table 1). The number of young adult binge drinkers was increased by incident binge drinking among those who did not report binge drinking in adolescence: one-third of the males and females. Only $4.4 \%$ of males and $9.5 \%$ of females who were adolescent binge drinkers did not report binge drinking in adulthood.

Past-week binge drinking ( $5+$ standard drinks of $10 \mathrm{~g}$ alcohol on a day) across adolescence (figure 2A) increased in males from $14.4 \%$ in wave 2 (mean age 15.5 years) to $31.1 \%$ in wave 6 (17.4 years) and in females from $7.6 \%$ to $15.0 \%$. Persistent adolescent pastweek binge drinking (across 2+ adolescent waves) was reported by one in three males $(31.8 \%)$ and one in seven females (15.3\%; table 1$)$. In the adult waves, the prevalence of binge drinking was higher for males and females than in the adolescent phase and levels consumed by males were higher than those by females. In adulthood (table 1 and figure 2A), over $80 \%$ of males reported binge drinking on at least one adult wave and more than half of the females did so. Six in $10(59.1 \%)$ males and one in four (24.5\%) females reported binge drinking across multiple adult waves (table 1).

\section{Past-week heavy binge drinking}

Just under half of the males $(45.6 \%)$ and a third of the females $(36.2 \%)$ reported past-week heavy binge drinking at least once during adolescence or young adulthood (table 2). Sixty-one per cent of males and $42 \%$ of females who reported heavy binge drinking in adolescence continued into young adulthood. Of those who engaged in heavy binge drinking at any wave, 58\% first reported doing so in young adulthood.

During adolescence, males and females reported similar levels of heavy binge use at each wave but males $(7.9 \%)$ were more likely to report heavy binge drinking on multiple adolescent waves than females $(4.7 \%$; table 2). Past-week heavy binge drinking did not increase substantially until the young adult waves (figure 2B). Around two in five males and one in four females reported past-week heavy binge drinking on at least one adult wave (table 2). At ages 20 and 24 years, around $20 \%$ of males and $13 \%$ of females reported heavy binge drinking. There was a decline in past-week heavy binge drinking by age 29 years.

\section{Young adult binge and heavy binge alcohol use among adolescent-onset binge drinkers}

Levels of past-week binge and heavy binge drinking in adulthood, among adolescent-onset binge and heavy binge drinkers, are presented in figure 3. Males with adolescent-onset binge drinking were more likely to continue binge drinking in adulthood than females (figure $3 \mathrm{~A})$ : around 7 in 10 males reported doing so, compared to fewer than half of the females. By 29 years, female adolescent-onset binge drinkers had substantially lower levels of binge drinking than in earlier waves, and much lower levels than males. Levels of adult heavy binge drinking did not differ markedly by sex among adolescent-onset binge drinkers; around 20-30\% reported past-week heavy binge drinking at ages 20 and 24, with lower levels at 29 years (wave 9; figure 3A). Among adolescent-onset heavy binge drinkers, the patterns and levels followed a similar sex pattern to that in adolescent-onset binge drinkers (figure 3B).

Table 3 reports associations between adolescent characteristics and binge and heavy binge drinking at any adult wave in adolescent-onset binge drinkers $(n=821)$. At a univariate level, being male and reporting adolescent antisocial behaviour or negative consequences of alcohol use in adolescence were associated with the reporting of young adult binge and heavy binge drinking in the past week. In multivariable analyses that included all covariates, the associations between adult 
Table 1 Past week binge drinking during adolescence and young adulthood, by sex

\begin{tabular}{|c|c|c|c|c|c|c|c|c|c|}
\hline & \multicolumn{9}{|c|}{ Binge drinking in the past week } \\
\hline & \multicolumn{3}{|c|}{ Males $(\mathrm{N}=935)$} & \multicolumn{3}{|c|}{ Females $(\mathrm{N}=999)$} & \multicolumn{3}{|c|}{ Total $(\mathrm{N}=1934)$} \\
\hline & $\bar{n}$ & Per cent & $(95 \% \mathrm{Cl})$ & $\bar{n}$ & Per cent & $(95 \% \mathrm{Cl})$ & $\bar{n}$ & Per cent & $(95 \% \mathrm{Cl})$ \\
\hline \multicolumn{10}{|l|}{ Adolescent phase (waves 2-6) } \\
\hline \multicolumn{10}{|l|}{ Binge drinking by wave } \\
\hline Wave 2 (mean age 15.5 years) & 135 & 14.4 & (12.1 to 16.7$)$ & 76 & 7.6 & (5.90 to 9.30$)$ & 211 & 10.9 & (9.50 to 12.3$)$ \\
\hline Wave 3 (mean age 15.9 years) & 170 & 18.1 & (15.5 to 20.7$)$ & 96 & 9.6 & (7.50 to 11.7$)$ & 265 & 13.7 & (12.1 to 15.4$)$ \\
\hline Wave 4 (mean age 16.4 years) & 208 & 22.3 & (19.3 to 25.3 ) & 140 & 14.1 & (11.8 to 16.3 ) & 349 & 18.0 & (16.2 to 19.9$)$ \\
\hline Wave 5 (mean age 16.8 years) & 265 & 28.3 & ( 25.1 to 31.5 ) & 152 & 15.2 & (12.9 to 17.6$)$ & 417 & 21.6 & (19.6 to 23.5$)$ \\
\hline Wave 6 (mean age 17.4 years) & 291 & 31.1 & (28.0 to 34.3 ) & 150 & 15.0 & (12.6 to 17.4$)$ & 441 & 22.8 & (20.8 to 24.8$)$ \\
\hline \multicolumn{10}{|l|}{ Number of adolescent waves of any binge drinking } \\
\hline Never & 453 & 48.5 & (45.0 to 52.0$)$ & 660 & 66.1 & (63.0 to 69.1$)$ & 1113 & 57.6 & (55.2 to 60.0$)$ \\
\hline 1 wave & 184 & 19.7 & (16.8 to 22.6$)$ & 186 & 18.6 & (16.0 to 21.2$)$ & 370 & 19.1 & (17.1 to 21.1$)$ \\
\hline $2+$ waves & 297 & 31.8 & (28.5 to 35.1 ) & 153 & 15.3 & (13.0 to 17.7$)$ & 451 & 23.3 & (21.3 to 25.3$)$ \\
\hline \multicolumn{10}{|l|}{ Young adult phase (waves 7-9) } \\
\hline \multicolumn{10}{|l|}{ Binge drinking by wave } \\
\hline Wave 7 (mean age 20.7 years) & 509 & 54.5 & (51.1 to 57.9 ) & 318 & 31.8 & (28.7 to 34.9 ) & 827 & 42.8 & (40.4 to 45.1$)$ \\
\hline Wave 8 (mean age 24.1 years) & 550 & 58.8 & (55.2 to 62.4$)$ & 335 & 33.5 & (30.3 to 36.7$)$ & 885 & 45.8 & (43.3 to 48.2$)$ \\
\hline Wave 9 (mean age 29.0 years) & 524 & 56.1 & (52.3 to 59.8$)$ & 233 & 23.3 & (20.2 to 26.4 ) & 757 & 39.2 & (36.6 to 41.8$)$ \\
\hline \multicolumn{10}{|l|}{ Number of adult waves of any binge drinking } \\
\hline Never & 178 & 19.1 & (16.2 to 21.9$)$ & 437 & 43.8 & (40.4 to 47.1$)$ & 616 & 31.8 & (29.6 to 34.1$)$ \\
\hline 1 wave & 204 & 21.8 & (18.9 to 24.8$)$ & 316 & 31.7 & (28.4 to 35.0$)$ & 521 & 26.9 & (24.7 to 29.1$)$ \\
\hline 2+ waves & 552 & 59.1 & (55.7 to 62.5$)$ & 245 & 24.5 & (21.5 to 27.6$)$ & 798 & 41.2 & (38.8 to 43.7$)$ \\
\hline \multicolumn{10}{|c|}{ Continuity and discontinuity from adolescence (waves 2-6) to young adulthood (waves 7-9) } \\
\hline None in either phase & 137 & 14.7 & (12.2 to 17.2$)$ & 342 & 34.2 & (31.0 to 37.5$)$ & 479 & 24.8 & (22.7 to 26.9$)$ \\
\hline Incident in young adulthood & 316 & 33.8 & (30.3 to 37.3 ) & 318 & 31.9 & (28.7 to 35.0$)$ & 634 & 32.8 & (30.4 to 35.2$)$ \\
\hline Remitted by young adulthood (adolescence only) & 41 & 4.4 & (2.80 to 6.00$)$ & 95 & 9.5 & (7.50 to 11.6$)$ & 136 & 7.1 & (5.80 to 8.30$)$ \\
\hline Continuing in young adulthood (both phases) & 441 & 47.1 & (43.5 to 50.7 ) & 244 & 24.4 & (21.6 to 27.2$)$ & 684 & 35.4 & (33.1 to 37.7 ) \\
\hline
\end{tabular}



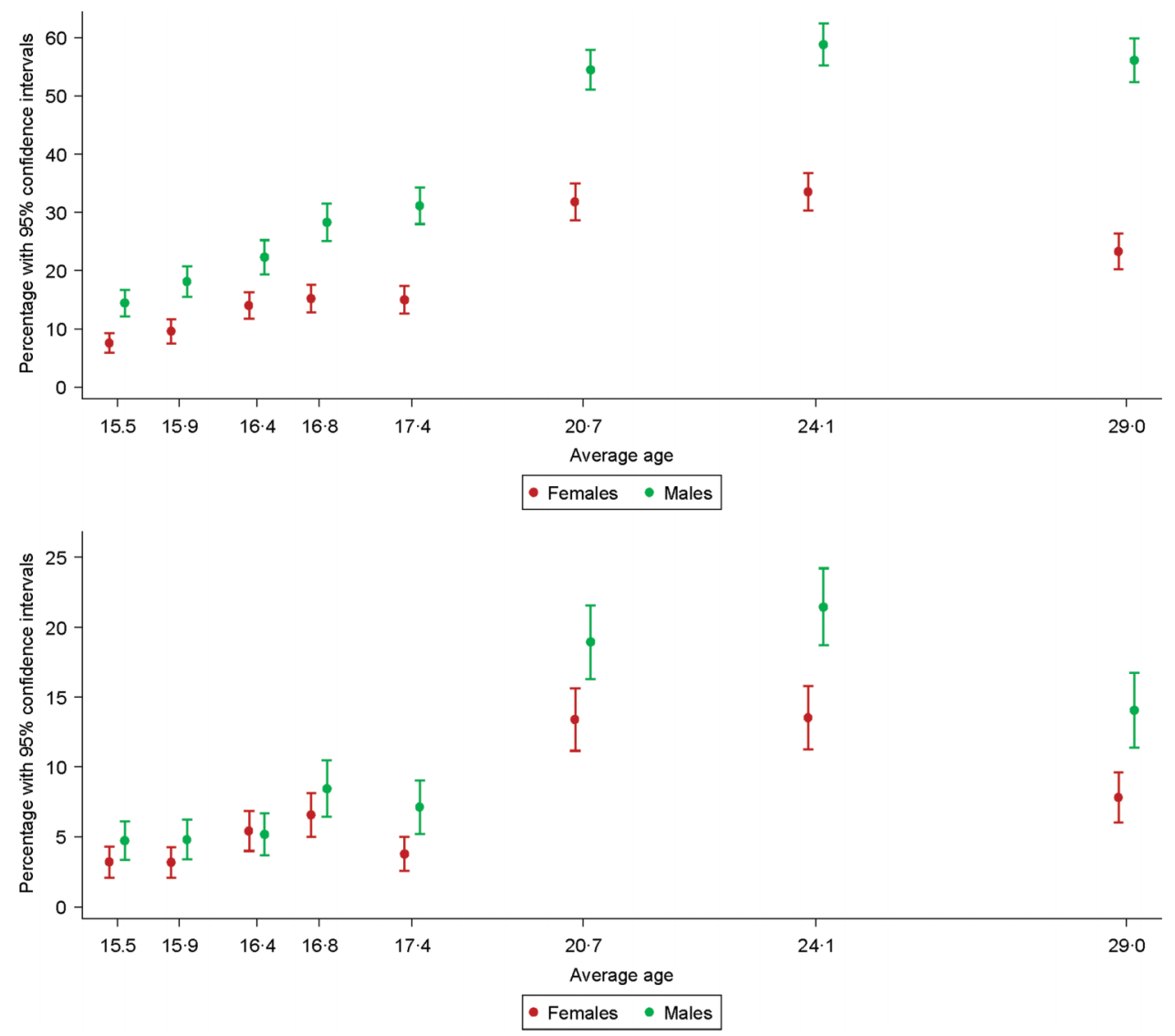

Figure 2 (A) Levels of past week binge alcohol use among males and females (5 or more standard drinks on a day in the past week) by age. (B) Levels of past week 'heavy binge' alcohol use among males and females (11 or more standard drinks on a day in the past week for females, 20 or more for males) by age.

bingeing and female gender were substantially unchanged (for young adult binge OR 0.23 , 95\% CI 0.13 to 0.40 ; for young adult heavy binge use OR 0.63 , $95 \%$ CI 0.43 to 0.92$)$. Associations with behavioural characteristics were substantially attenuated when adjusted for sex and other characteristics, with the strongest independent effect being an increase in the odds of young adult binge drinking if sexual risk taking had occurred in adolescence.

\section{DISCUSSION}

Consistent with the cross-sectional surveys in England, ${ }^{29}$ the USA and Europe ${ }^{5}{ }^{9}$ binge drinking was highly prevalent in both sexes and normative in young Australian males. A substantial minority also engaged in heavy binge drinking (drinking more than 20 drinks on an occasion). Over half of the males and a third of the females reported binge drinking in the past week at some time during adolescence, and one in five males and one in seven females reported what we defined as 'heavy binge drinking'.

The overwhelming majority of those who reported binge drinking in adolescence continued to do so in young adulthood. Even if past-week binge drinking was not reported in the teens, it was reported in at least one wave in young adulthood by $70 \%$ of males and $48 \%$ of females who did not report binge drinking at any time in adolescence. Interestingly, our findings about the continuity of past-week binge drinking from adolescence to young adulthood contrasted somewhat with the findings of a Norwegian cohort study, where considerable discontinuity was observed, and where they estimated that eliminating all adolescent hazardous drinking would only reduce adult hazardous drinking by $10 \% .^{30}$

Among those who reported binge drinking in adolescence, variables that predicted binge and heavy binge drinking in young adulthood included: regular (weekly+) cannabis use, antisocial behaviour and early onset sexual activity. The most consistent predictors of adult binge and heavy binge drinking were reporting adverse consequences of alcohol use in adolescence, namely 'intense drinking' (could not remember the night before because of drinking), social problems, sexual risk taking and physical harm. Adolescent binge drinkers who engaged in other risky behaviours, and who had experienced negative consequences of alcohol use, were most likely to continue drinking at these levels in adulthood. In multivariable regression analysis, the strongest independent predictor of adult binge drinking among adolescent binge drinkers was being male. 
Table 2 Past week heavy binge drinking during adolescence and young adulthood, by sex

\begin{tabular}{|c|c|c|c|c|c|c|c|c|c|}
\hline & \multicolumn{9}{|c|}{ Heavy binge drinking in the past week } \\
\hline & \multicolumn{3}{|c|}{ Males (N=935) } & \multicolumn{3}{|c|}{ Females $(\mathrm{N}=999)$} & \multicolumn{3}{|c|}{ Total $(\mathrm{N}=1934)$} \\
\hline & $\mathrm{n}$ & Per cent & $(95 \% \mathrm{Cl})$ & $\mathbf{n}$ & Per cent & $(95 \% \mathrm{Cl})$ & $\mathrm{n}$ & Per cent & $(95 \% \mathrm{Cl})$ \\
\hline \multicolumn{10}{|l|}{ Adolescent phase (waves 2-6) } \\
\hline \multicolumn{10}{|l|}{ Heavy binge drinking by wave } \\
\hline Wave 2 (mean age 15.5 years) & 44 & 4.8 & (3.40 to 6.10$)$ & 32 & 3.2 & (2.10 to 4.30$)$ & 77 & 4.0 & (3.10 to 4.80$)$ \\
\hline Wave 3 (mean age 15.9 years) & 45 & 4.8 & (3.40 to 6.20$)$ & 32 & 3.2 & (2.10 to 4.30$)$ & 77 & 4.0 & (3.10 to 4.90$)$ \\
\hline Wave 4 (mean age 16.4 years) & 49 & 5.2 & (3.70 to 6.70$)$ & 54 & 5.4 & (4.00 to 6.90$)$ & 103 & 5.3 & (4.30 to 6.30$)$ \\
\hline Wave 5 (mean age 16.8 years) & 79 & 8.5 & (6.40 to 10.5$)$ & 66 & 6.6 & (5.00 to 8.10$)$ & 145 & 7.5 & (6.20 to 8.80$)$ \\
\hline Wave 6 (mean age 17.4 years) & 67 & 7.1 & (5.20 to 9.00$)$ & 38 & 3.8 & (2.60 to 5.00$)$ & 105 & 5.4 & (4.30 to 6.50$)$ \\
\hline \multicolumn{10}{|c|}{ Number of adolescent waves of any heavy binge drinking } \\
\hline Never & 755 & 80.7 & (78.1 to 83.4$)$ & 847 & 84.7 & (82.5 to 87.0$)$ & 1601 & 82.8 & (81.1 to 84.5$)$ \\
\hline 1 wave & 106 & 11.4 & (9.10 to 13.6$)$ & 106 & 10.6 & (8.60 to 12.5$)$ & 212 & 11.0 & (9.50 to 12.4$)$ \\
\hline $2+$ waves & 74 & 7.9 & (6.10 to 9.70$)$ & 47 & 4.7 & (3.30 to 6.00$)$ & 121 & 6.2 & (5.10 to 7.30$)$ \\
\hline \multicolumn{10}{|l|}{ Young adult phase (waves 7-9) } \\
\hline \multicolumn{10}{|l|}{ Heavy binge drinking by wave } \\
\hline Wave 7 (mean age 20.7 years) & 177 & 18.9 & (16.3 to 21.6$)$ & 134 & 13.4 & (11.2 to 15.6$)$ & 311 & 16.1 & (14.4 to 17.8$)$ \\
\hline Wave 8 (mean age 24.1 years) & 201 & 21.4 & (18.7 to 24.2$)$ & 135 & 13.5 & (11.3 to 15.8$)$ & 336 & 17.4 & (15.6 to 19.1$)$ \\
\hline Wave 9 (mean age 29.0 years) & 132 & 14.1 & (11.4 to 16.7$)$ & 78 & 7.8 & (6.10 to 9.60$)$ & 210 & 10.8 & (9.30 to 12.4$)$ \\
\hline \multicolumn{10}{|l|}{ Number of adult waves of any heavy binge drinking } \\
\hline Never & 579 & 62 & (58.7 to 65.3$)$ & 726 & 72.7 & (69.7 to 75.6$)$ & 1305 & 67.5 & (65.2 to 69.7$)$ \\
\hline 1 wave & 230 & 24.6 & (21.4 to 27.8$)$ & 212 & 21.2 & (18.5 to 23.9$)$ & 442 & 22.8 & (20.7 to 25.0 ) \\
\hline $2+$ waves & 125 & 13.4 & (10.9 to 15.9$)$ & 62 & 6.2 & (4.60 to 7.70$)$ & 187 & 9.7 & (8.20 to 11.1$)$ \\
\hline \multicolumn{10}{|c|}{ Continuity and discontinuity from adolescence (waves 2-6) to young adulthood (waves 7-9) } \\
\hline None in either phase & 508 & 54.4 & (50.9 to 57.8$)$ & 638 & 63.8 & (60.7 to 66.9$)$ & 1146 & 59.2 & (56.9 to 61.6$)$ \\
\hline Incident in young adulthood & 247 & 26.4 & (23.3 to 29.5$)$ & 209 & 20.9 & (18.3 to 23.5$)$ & 456 & 23.6 & (21.5 to 25.6$)$ \\
\hline Remitted by young adulthood (adolescence only) & 71 & 7.6 & (5.80 to 9.50$)$ & 88 & 8.8 & (7.00 to 10.7$)$ & 160 & 8.2 & (6.90 to 9.60$)$ \\
\hline Continuing in young adulthood (both phases) & 109 & 11.6 & (9.30 to 14.0$)$ & 64 & 6.4 & (4.80 to 8.10$)$ & 173 & 9.0 & (7.60 to 10.3 ) \\
\hline
\end{tabular}

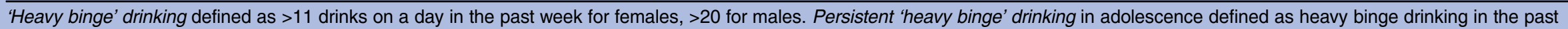
week on two or more waves across the adolescent waves (waves 2-6). 

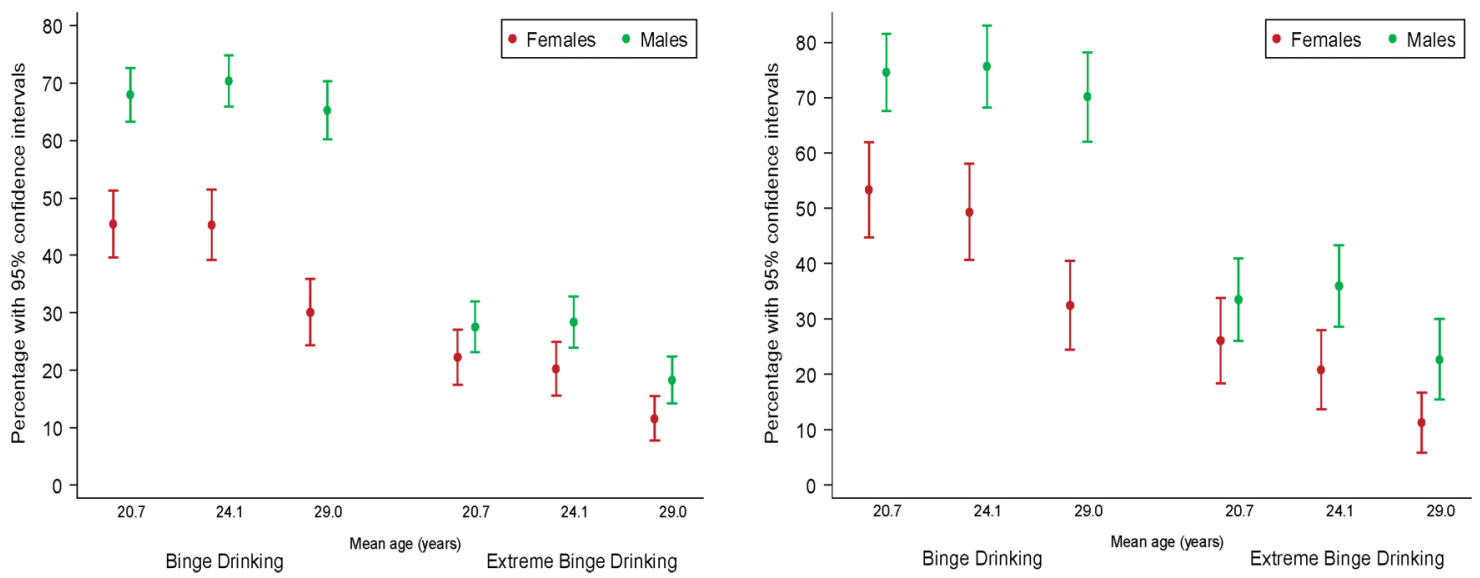

Figure 3 (A) Levels of past week binge and 'heavy binge' drinking for males and females who reported binge drinking at one or more waves in adolescence, by age. (B) Levels of past week binge and 'heavy binge' drinking for males and females who reported 'heavy binge' drinking at one or more waves in adolescence, by age.

\section{Limitations}

The following limitations need to be acknowledged. First, non-response in longitudinal studies is often associated with alcohol and drug use. We used multiple imputation to minimise the impact of this potential bias, but this method carries its own assumptions and it is difficult to assess exactly how much residual bias might remain. The method of multiple imputation also assumes that data were missing at random. This is unlikely to be strictly true, but the method is strengthened by the inclusion of auxiliary variables in the imputation model.

Second, our data do not capture the full extent of binge drinking in this cohort because not all binge alcohol use will have been captured within the 1 week reference period. Both these limitations mean that our findings on levels of binge drinking may underestimate total exposure to these levels of drinking overall and over time.

Third, all data were based on self-report. There is reasonable evidence that young people's reports of alcohol use are reliable and valid when they are made in a confidential manner and without any consequences for disclosing use (as was the case here). ${ }^{31} 32$

Fourth, we used the same definition of binge and heavy binge drinking in adolescents and young adults. It is quite likely that the same amount of alcohol will have a greater adverse impact on adolescents than on adults. Notwithstanding these limitations, this study has provided unique prospective data on the persistence of a prevalent and hazardous drinking pattern from adolescence into adulthood.

We have clearly identified that binge alcohol use is a common behaviour among adolescents, and that it is likely to persist into young adulthood. These patterns of binge drinking in adolescence are a public health concern for two reasons. First, heavy alcohol use substantially increases the risks of: motor vehicle accidents, other injuries, alcohol-related assaults and suicides in young people. ${ }^{33}$ Second, the longer-term health effects of persistent binge drinking during adulthood include alcohol dependence, liver disease and cancer. In most adolescent binge drinkers, binge drinking was clearly not just an 'adolescent phase'; it was a pattern that persisted into young adulthood. There is an urgent need to understand why such high levels of alcohol use in adolescence continue into young adulthood.

Social acceptability, ready availability and low cost of alcohol are likely to be important drivers of early initiation into binge drinking and continuing high levels of consumption. Both the taste ${ }^{34}$ and packaging ${ }^{35}$ of premixed drinks are particularly attractive to young people; exposure to some forms of advertising is also associated with increased consumption, ${ }^{36}$ as are increased numbers of outlets selling alcohol, ${ }^{37-39}$ extended opening hours ${ }^{40}{ }^{41}$ and reduced alcohol taxes ${ }^{40} 42$ (though only applied similarly across products. ${ }^{43}$ ) The persistence of binge drinking into young adulthood may also be related to a delay in 'maturing out' of drinking as a result of the postponement in recent cohorts of major social role transitions such as marriage and parenthood into later adulthood. ${ }^{44}$

\section{CONCLUSIONS}

Alcohol is one of the biggest risk factors for disease burden among young people. Heavy consumption in young people is common and persistence into young adulthood is much more likely than not. There is a need to develop interventions that explicitly acknowledge that prevention confined to adolescence alone is insufficient. Clearly, there is much work still to be carried out in that area, given the incredibly high exposure not only to any alcohol use, but also to binge alcohol use across the adolescent years, often repeatedly. It is also apparent that there is work to be carried out in young adulthood since most of the heavy binge drinking began then, once participants were legally allowed to drink, and past the age at which most prevention 
Table 3 Predictors of binge alcohol use in young adulthood among adolescent 'binge' alcohol drinkers (ie, those who had past-week binge drinking on at least one wave during adolescence, waves $2-6 ; n=821$ )

\begin{tabular}{|c|c|c|c|c|c|c|c|c|}
\hline \multirow[b]{3}{*}{ Adolescent predictors among adolescent 'binge' drinkers, $n=821$ : } & \multicolumn{4}{|c|}{ Young adult 'binge' drinking } & \multicolumn{4}{|c|}{ Young adult 'heavy binge' drinking } \\
\hline & \multicolumn{2}{|c|}{ Modelled separately } & \multicolumn{2}{|c|}{ Modelled jointly } & \multicolumn{2}{|c|}{ Modelled separately } & \multicolumn{2}{|c|}{ Modelled jointly } \\
\hline & $\overline{\text { OR }}$ & $(95 \% \mathrm{Cl})$ & $\overline{\text { OR }}$ & $(95 \% \mathrm{Cl})$ & $\overline{\text { OR }}$ & $(95 \% \mathrm{Cl})$ & $\overline{\text { OR }}$ & $(95 \% \mathrm{Cl})$ \\
\hline Female & 0.24 & (0.15 to 0.39$)$ & 0.23 & $(0.13$ to 0.40$)$ & 0.67 & (0.49 to 0.92$)$ & 0.63 & $(0.43$ to 0.92$)$ \\
\hline Daily smoking & 1.20 & (0.79 to 1.81$)$ & 1.12 & (0.69 to 1.82$)$ & 1.29 & (0.94 to 1.77$)$ & 1.01 & $(0.70$ to 1.46$)$ \\
\hline Weekly/daily cannabis use & 1.65 & (0.96 to 2.82 ) & 1.05 & (0.54 to 2.03$)$ & 1.57 & (1.11 to 2.24$)$ & 1.06 & (0.71 to 1.60$)$ \\
\hline Antisocial behaviour & 1.70 & (1.12 to 2.59$)$ & 0.99 & (0.60 to 1.63$)$ & 1.59 & (1.16 to 2.18$)$ & 1.06 & (0.74 to 1.52$)$ \\
\hline Early onset sexual activity (<16 years) & 1.46 & (0.92 to 2.33 ) & 1.04 & (0.60 to 1.83$)$ & 1.53 & (1.09 to 2.14$)$ & 1.02 & (0.69 to 1.49$)$ \\
\hline \multicolumn{9}{|l|}{ Adolescent mental health problems } \\
\hline CIS $>11,0$ waves & 1 & & 1 & & 1 & & 1 & \\
\hline CIS $>11,1$ wave & 0.81 & (0.42 to 1.57$)$ & 0.90 & (0.44 to 1.81$)$ & 1.23 & (0.81 to 1.87$)$ & 1.15 & (0.74 to 1.77$)$ \\
\hline CIS $>11,2+$ waves & 0.60 & (0.37 to 0.97$)$ & 0.83 & (0.48 to 1.46$)$ & 1.05 & (0.74 to 1.49$)$ & 0.99 & (0.64 to 1.52$)$ \\
\hline \multicolumn{9}{|l|}{ Adolescent consequences attributed to alcohol use } \\
\hline Intense drinking* & 1.54 & (1.00 to 2.36$)$ & 1.45 & (0.84 to 2.50$)$ & 1.77 & (1.28 to 2.43$)$ & 1.41 & (0.99 to 2.00$)$ \\
\hline Social problems & 1.34 & (0.85 to 2.10$)$ & 1.25 & $(0.72$ to 2.18$)$ & 1.63 & (1.16 to 2.31$)$ & 1.23 & (0.83 to 1.83$)$ \\
\hline Physical harm $\ddagger$ & 1.92 & (1.13 to 3.26$)$ & 1.25 & (0.64 to 2.44$)$ & 1.96 & (1.37 to 2.81$)$ & 1.29 & (0.84 to 1.96$)$ \\
\hline Sexual risk taking§ & 1.75 & (1.01 to 3.03$)$ & 1.51 & (0.77 to 2.97 ) & 2.09 & (1.44 to 3.03$)$ & 1.64 & (1.07 to 2.53 ) \\
\hline
\end{tabular}

'Binge' drinking defined as five or more drinks in 1 day in the past week. 'Heavy binge' drinking defined as $>11$ drinks in 1 day in the past week for females, $>20$ for males. Note that $21-$

22 years=wave $7 ; 24-25$ years=wave $8 ; 28-29$ years=wave 9

${ }^{*}$ Could not remember what said or did the night before as a result of alcohol use.

tLost friends, school trouble, argued with family as a result of alcohol use.

flnjuries, accidents, violence attributed to their alcohol use.

$\S$ Regretted having sex, or had sex without protection or contraceptives as a result of alcohol use. 
messages are targeted. There is an increasingly delayed uptake of social role transitions; it is unclear whether such shifts are related to the patterns of alcohol consumption we observed here. The adoption of policies and interventions, including those to reduce alcohol availability (via shortened trading hours and fewer outlets), increase cost (via taxation) and discourage drinking to intoxication, may assist in reducing binge alcohol use in future cohorts of young people.

Contributors LD, GP, WS and CO conceived of the study. CO and HR conducted the analyses. LD led the writing of the manuscript. All authors commented on the analytic plan and interpretation and contributed to the editing and final approval of the manuscript.

Funding Funding for the work undertaken for this manuscript was provided by Australian Rotary Health. The broader study was funded through the National Health and Medical Research Council (NHMRC). (NHMRC grant number 1008271, LD fellowships 510279 and 1041472, GP fellowship 1019887, WH fellowship 569738.)

Competing interests LD and GP are supported by NHMRC Principal and Senior Principal Research Fellowships, respectively. WH is supported by an NHMRC Australia Fellowship. The National Drug and Alcohol Research Centre at the University of NSW was supported by funding from the Australian Government under the Substance Misuse Prevention and Service Improvements Grants Fund.

Ethics approval The Ethics in Human Research Committee of the Royal Children's Hospital, Melbourne approved all data collection protocols.

Provenance and peer review Not commissioned; externally peer reviewed.

Data sharing statement No additional data are available.

Open Access This is an Open Access article distributed in accordance with the Creative Commons Attribution Non Commercial (CC BY-NC 3.0) license, which permits others to distribute, remix, adapt, build upon this work noncommercially, and license their derivative works on different terms, provided the original work is properly cited and the use is non-commercial. See: http:// creativecommons.org/licenses/by-nc/3.0/

\section{REFERENCES}

1. Gore FM, Bloem PJN, Patton GC, et al. Global burden of disease in young people aged 10-24 years: a systematic analysis. Lancet 2011;377:2093-102

2. World Health Organization. Global status report on alcohol and health. Geneva: World Health Organization, 2009.

3. World Health Organization. The global burden of disease: 2004 update. Geneva: World Health Organization, 2008.

4. Australian Institute of Health and Welfare. National Drug Strategy Household Survey 2010_detailed findings. Canberra: Australian Institute of Health and Welfare, 2011.

5. Currie C, Zanotti C, Morgan A, et al. Social determinants of health and well-being among young people. Health behaviour in school-aged children (HBSC) study: International report from the 2009/2010 survey. Health Policy for Children and Adolescents, No. 6. Copenhagen: WHO Regional Office for Europe, 2012.

6. Pickett W, Schmid H, Boyce WF, et al. Multiple risk behavior and injury: an international analysis of young people. Arch Pediatr Adolesc Med 2002;156:886-93.

7. Schmid H, Ter Bogt T, Godeau E, et al. Drunkenness among young people: a cross-national comparison. J Stud Alcohol 2003;64:650-61.

8. Wechsler H, Davenport A, Dowdall G, et al. Health and behavioral consequences of binge drinking in college. JAMA 1994;272:1672-7.

9. Hibell B, Guttormsson U, Ahlström S, et al. The 2011 ESPAD Report: Substance use among students in 36 European Countries. Stockholm: The Swedish Council for Information on Alcohol and other Drugs (CAN) The European Monitoring Centre for Drugs and Drug Addiction (EMCDDA), Council of Europe, Co-operation Group to Combat Drug Abuse and Illicit Trafficking in Drugs (Pompidou Group), 2012.

10. Australian Institute of Health and Welfare. National Drug Strategy Household Survey 2007-detailed findings. Canberra: Australian Institute of Health and Welfare, 2008.
11. Livingston M, Laslett AM, Dietze P. Individual and community correlates of young people's high-risk drinking in Victoria, Australia. Drug Alcohol Depend 2008;98:241-8.

12. Beyers JM, Toumbourou JW, Catalano RF, et al. A cross-national comparison of risk and protective factors for adolescent substance use: the United States and Australia. J Adolesc Health 2004;35:3-16.

13. Oesterle S, Hill KG, Hawkins JD, et al. Adolescent heavy episodic drinking trajectories and health in young adulthood. J Stud Alcohol 2004;65:204.

14. Guttmannova K, Hill KG, Bailey JA, et al. Examining explanatory mechanisms of the effects of early alcohol use on young adult alcohol dependence. J Stud Alcohol Drugs 2012;73:379.

15. Guttmannova K, Bailey JA, Hill KG, et al. Sensitive periods for adolescent alcohol use initiation: predicting the lifetime occurrence and chronicity of alcohol problems in adulthood. J Stud Alcohol Drugs 2011;72:221.

16. Lee JO, Hill KG, Guttmannova K, et al. The effects of general and alcohol-specific peer factors in adolescence on trajectories of alcohol abuse disorder symptoms from 21 to 33 years. Drug Alcohol Depend 2012;121:213-19.

17. Guo J, Hawkins JD, Hill KG, et al. Childhood and adolescent predictors of alcohol abuse and dependence in young adulthood. J Stud Alcohol 2001;62:754.

18. Guo J, Collins LM, Hill KG, et al. Developmental pathways to alcohol abuse and dependence in young adulthood. J Stud Alcohol 2000;61:799.

19. Hawkins JD, Graham JW, Maguin E, et al. Exploring the effects of age of alcohol use initiation and psychosocial risk factors on subsequent alcohol misuse. J Stud Alcohol 1997;58:280.

20. McCambridge J, McAlaney J, Rowe R. Adult consequences of late adolescent alcohol consumption: a systematic review of cohort studies. PLoS Med 2011;8:e1000413.

21. Patton GC, Carlin JB, Coffey C, et al. The course of early smoking: a population-based cohort study over three years. Addiction 1998;93:1251-60.

22. Patton GC, Harris R, Carlin J, et al. Adolescent suicidal behaviours: a population-based study of risk. Psycholo Med 1997;27:715-24.

23. Paperny D, Aono J, Lehman R, et al. Computer-assisted detection and intervention in adolescent high-risk health behaviours. J Paediatr 1990;116:456-62.

24. Moffitt TE, Silva PA. Self-reported delinquency-results from an instrument for New-Zealand. Aust N Z J Criminol 1988;21:227-40.

25. Lewis G, Pelosi AJ, Araya R, et al. Measuring psychiatric disorder in the community: a standardized assessment for use by lay interviewers. Psychol Med 1992;22:465-86.

26. Rubin DB. Multiple imputation for nonresponse in surveys. New York: John Wiley and Sons, 2004.

27. Bernaards CA, Belin TR, Schafer JL. Robustness of a multivariate normal approximation for imputation of incomplete binary data. Stat Med 2007;26:1368-82.

28. Stata Corporation. Intercooled Stata 12.0 for Windows. College Station, TX: STATA Corporation, 2011.

29. Fuller E. Drug use, smoking and drinking among young people in England in 2010. London: National Centre for Social Research, National Foundation for Educational Research in England, 2011.

30. Norström T, Pape H. Associations between adolescent heavy drinking and problem drinking in early adulthood: implications for prevention. J Stud Alcohol Drugs 2012;73:542.

31. Darke S. Self-report among injecting drug users: a review [see comments]. Drug Alcohol Depend 1998;51:253-63; discussion 267-8.

32. Williams CL, Toomey TL, McGovern PG, et al. Development, reliability, and validity of self-reported alcohol-use measures with young adolescents. J ChildAdolesc Subst Abus 1995;4:17-40.

33. Mathews RRS, Hall WD, Vos T, et al. What are the major drivers of prevalent disability burden in young Australians? Med J Aust 2011;194:232-5.

34. Copeland J, Stevenson RJ, Gates P, et al. Young Australians and alcohol: the acceptabllity of ready-to-drink (RTD) alcoholic beverages among 12-30-year-olds. Addiction 2007;102:1740-6.

35. Gates P, Copeland J, Stevenson RJ, et al. The influence of product packaging on young people's palatability rating for RTDS and other alcoholic beverages. Alcohol Alcohol 2007;42:138-42.

36. Jones SC, Magee CA. Exposure to alcohol advertising and alcohol consumption among Australian adolescents. Alcohol Alcohol 2011;46:630-7.

37. Livingston M. Alcohol outlet density and harm: comparing the impacts on violence and chronic harms. Drug Alcohol Rev 2011;30:515-23. 
38. Livingston M, Chikritzhs T, Room R. Changing the density of alcohol outlets to reduce alcohol-related problems. Drug Alcohol Revw 2007;26:557-66.

39. Scribner RA, Cohen DA, Fisher W. Evidence of a structural effect for alcohol outlet density: a multilevel analysis. Alcohol: Clin Exp Res 2006;24:188-95.

40. Cobiac L, Vos T, Doran C, et al. Cost-effectiveness of interventions to prevent alcohol-related disease and injury in Australia. Addiction 2009;104:1646-55.

41. Popova S, Giesbrecht N, Bekmuradov D, et al. Hours and days of sale and density of alcohol outlets: impacts on alcohol consumption and damage: a systematic review. Alcohol Alcohol 2009;44:500-16.
42. Wagenaar AC, Tobler AL, Komro KA. Effects of alcohol tax and price policies on morbidity and mortality: a systematic review. Am J Public Health 2010;100:2270.

43. Kisely SR, Pais J, White A, et al. Effect of the increase in "alcopops" tax on alcohol-related harms in young people: a controlled interrupted time series. Med J Aust 2011;195: 690-3.

44. Staff J, Schulenberg JE, Maslowsky J, et al. Substance use changes and social role transitions: proximal developmental effects on ongoing trajectories from late adolescence through early adulthood. Dev Psychopathol 2010;22:917-32. 